\title{
OPTIMASI DISTRIBUSI TRUK PENGANGKUT SAMPAH MENGGUNAKAN ALGORITMA GENETIKA PADA SISTEM PENGELOLAAN SAMPAH KOTA BOGOR
}

\section{DISTRIBUTION OPTIMIZATION OF WASTE TRANSPORT TRUCK USING GENETIC ALGORITHM IN THE WASTE MANAGEMENT SYSTEM OF BOGOR CITY}

\author{
Khadijah Febriana $^{1)^{*}}$, Sri Wahjuni 1), dan Andes Ismayana ${ }^{2)}$ \\ ${ }^{1)}$ Departemen Ilmu Komputer,Fakultas Matematika dan Ilmu Pengetahuan Alam,Institut Pertanian Bogor \\ Jl. Meranti,Wing 20, Kampus IPB Dramaga, Bogor, 16680,Indonesia \\ E-mail : khadijahfebriana91@gmail.com \\ 2)Departemen Teknologi Industri Pertanian,Fakultas Teknologi Pertanian,Institut Pertanian Bogor
}

Makalah: Diterima 28 April 2019; Diperbaiki 20 November 2019; Disetujui 2 Desember 2019

\begin{abstract}
Waste is one of the problems faced by Bogor city, with waste production of 2,701 $\mathrm{m}^{3}$ per day. Waste management of Bogor city currently still has limited garbage facilities and infrastructure that make garbage not yet maximally resolved, including not having a regular schedule of truck distribution in serving sub-district waste. The aim of this research is to optimize the distribution of garbage transport trucks using genetic algorithms. The initial stage of the research carried out is the calculation of the waste generation projection based on population data from Badan Pusat Statistik with reference to SNI 19-3964-1994. Optimization with genetic algorithms consists of a selection process where this study uses the Roulette Wheel selection method, crossover, and mutation. The optimization process using genetic algorithms (GA) from the number of DLH trucks operating currently as many as 60 trucks in serving 490 polling stations (TPS) spread across six subdistricts in Bogor City, the distribution results are to West Bogor district 15 trucks, South Bogor district 13 trucks, East Bogor district 4 trucks, Central Bogor district 3 trucks, North Bogor 12 trucks, and 13 trucks for Tanah Sareal district. Optimization testing with GA showed that with 60 dump truck type trucks with a capacity of $7 \mathrm{~m}^{3}$ operating and transporting as many as 3 rit, the garbage transported is only about $46.64 \%$ of the total waste. To achieve the government's target regarding solid waste services of 80 until $85 \%$, 110 trucks are needed.
\end{abstract}

Keywords : genetic algorithm, optimization, scheduling

\section{ABSTRAK}

Sampah merupakan salah satu permasalahan yang dihadapi kota Bogor, dengan produksi sampah sebanyak $2.701 \mathrm{~m}^{3}$ per hari. Pengelolaan sampah kota Bogor saat ini masih memiliki keterbatasan sarana dan prasarana persampahan yang membuat sampah belum teratasi dengan maksimal,termasuk belum memiliki jadwal reguler pendistribusian truk dalam melayani sampah kecamatan. Tujuan penelitian ini adalah optimasi distribusi truk pengangkut sampah menggunakan algoritma genetika. Tahapan awal penelitian yang dilalui adalah penghitungan proyeksi timbulan sampah berdasarkan data jumlah penduduk dari Badan Pusat Statistik (BPS) dengan acuan SNI 19-3964-1994. Selanjutnya dilakukan optimasi dengan algoritma genetika (GA) yang terdiri dari proses seleksi individu menggunakan metode seleksi Roulette Wheel, crossover dan mutasi. Proses optimasi menggunakan algoritma genetika (GA) dari jumlah truk milik DLH yang beroperasi saat ini sebanyak 60 truk dalam melayani 490 TPS yang tersebar di enam kecamatan di Kota Bogor diperoleh hasil pendistribusian ke Bogor Barat 15 truk, Kecamatan Bogor Selatan 13 truk, Kecamatan Bogor Timur 4 truk, Kecamatan Bogor Tengah 3 truk, Bogor Utara 12 truk, dan 13 truk untuk Kecamatan Tanah Sareal. Pengujian optimasi dengan GA menunjukkan bahwa dengan 60 truk jenis dump truk berkapasitas $7 \mathrm{~m}^{3}$ yang beroperasi dan tiap truk mengangkut sebanyak 3 rit maka sampah yang diangkut hanya sekitar 46,64\% dari total sampah. Untuk memenuhi target pemerintah terkait layanan persampahan sebesar 80-85\% dibutuhkan 110 truk.

Kata kunci : algoritma genetika, optimasi, penjadwalan

\section{PENDAHULUAN}

Kota Bogor merupakan salah satu kota/kabupaten dari 100 smart cities indonesia (aptika.kominfo.go.id). Dalam upayanya pemerintah mencoba menerapkan teknologi maupun inovasi terbaru untuk pencapaian sebagai smart city diantaranya smart governance, smart living, smart health, smart branding, smart people dan smart environment. Untuk smart environment terkait dengan layanan kebersihan dan persampahan.

Kebersihan kota menjadi salah satu hal yang penting yang harus diperhatikan untuk kualitas hidup masyarakat. Berdasarkan data Badan Pusat Statistik (BPS) Kota Bogor tahun 2017 dengan Jumlah penduduk 1.081.009 jiwa yang diikuti pertumbuhan ekonomi mempengaruhi perubahan pola hidup masyarakat konsumtif di era digital saat ini (bappeda.kotabogor.go.id). Hal tersebut menjadi

*Penulis Korespodensi 
salah satu faktor yang berpengaruh terhadap peningkatan produksi sampah. Selain itu, kota Bogor yang merupakan destinasi wisata dan kuliner mingguan dapat menghasilkan sampah sekitar 2.700 $\mathrm{m}^{3}$ per harinya. Sampah masih menjadi permasalahan yang belum bisa diatasi dengan maksimal hingga saat ini.

Peningkatan produksi sampah setiap harinya tidak sebanding dengan kemampuan pengelolaan sampah yang ada. Saat ini pengelolaan sampah di kota Bogor masih menggunakan sistem kumpul-angkut-buang, dimana sampah dari sumber sampah seperti sampah rumah tangga misalnya, dikumpulkan menggunakan gerobak sampah dari tiap RT/RW untuk dipindahkan ke TPS terdekat, selanjutnya di angkut oleh truk pengangkut sampah milik Dinas Lingkungan Hidup (DLH) kota Bogor untuk dibuang ke Tempat Pembuangan Akhir (TPA) Galuga. Keterbatasan sarana dan prasarana yang ada saat ini membuat sampah belum diatasi secara maksimal. Jumlah truk pengangkut sampah jenis dump truck milik DLH berkapasitas $7 \mathrm{~m}^{3}$ yang beroperasi saat ini sebanyak 60 truk harus melayani 490 Tempat Penampungan Sementara (TPS) di kota Bogor. Kendala lainnya adalah kemacetan di beberapa ruas jalan menuju TPA galuga, menjadikan kemampuan operasional truk menjadi kurang optimal. Untuk itu diperlukan sebuah alat bantu untuk lebih mengoptimalkan pemanfaatan truk pengangkut sampah.

Algoritma genetika bisa diterapkan untuk proses optimasi karena sifat perubahan evolusi alamiahnya. Algoritma ini hanya melakukan sedikit perhitungan matematis dengan masalah yang ingin diselesaikan, mencari penyelesaian tanpa memperhatikan proses-proses yang berhubungan dengan masalah yang diselesaikan secara langsung. Selain itu operator-operator evolusi membuat algoritma genetika sangat efektif pada pencarian global (Zukhri, 2014). Pada penelitian terdahulu algoritma genetika digunakan untuk mengoptimalkan permasalahan dalam mencari solusi untuk kasus TSP (Traveling Salesman Problem) dengan jumlah titik yang harus dilalui 20 kota (Lukas et al., 2005). Dalam penelitian ini ditemukan solusi kota mana yang dijangkau dengan rute paling pendek. Penelitian Hasibuan et al. (2015) untuk mencari rute terbaik dalam jadwal angkut sampah di Dinas Kebersihan dan Pertamanan kota Pekanbaru juga menerapkan algoritma genetika. Penelitian lain yaitu mencari jalur alternatif menggunakan algoritma genetika dengan dipengaruhi jumlah node, jumlah iterasi yang dilakukan serta jumlah edge (Trianto et al., 2008). Algoritma genetika juga diterapkan pada kasus penjadwalan, diantaranya penelitian Mawaddah et al. (2006) yang melakukan optimasi penjadwalan ujian. Dalam penelitian ini jadwal perkuliahan yang dibuat sering mengalami kendala terkait ruangan dan jadwal mengajar dosen yang sering bertabrakan dengan jadwal mengajar di kelas lain pada hari dan jam yang sama. Selain itu, Muliadi (2014) juga menggunakan algoritma genetika pada sistem penjadwalan perkuliahan program studi ilmu komputer universitas lambung mangkurat.

Dengan adanya kendala keterbatasan jumlah truk dan ritase pengangkutanakibat kondisi lalu lintas Kota Bogor, maka diperlukan untuk melakukan optimasipendistribusian truk ke tiap kecamatan dengan metode algoritma genetika. Target yang ingin dicapai adalah meminimalisasi sisa sampah tidak terangkut di tiap kecamatan dalam upaya memenuhi target pemerintah untuk layanan pengangkutan sampah Kota Bogor sebesar 80-85\%.

\section{METODE PENELITIAN}

\section{Data Penelitian}

Penelitian ini dilakukan pada bulan Mei sampai Desember 2017. Data sampah dan palayanan persampahan Kota Bogor diperoleh dari hasil interview dengan Dinas Lingkungan Hidup Kota Bogor. Data penduduk diperoleh dari badan pusat statistik kota Bogor.

\section{Tahapan Penelitian}

Pada penelitian ini ada beberapa tahapan yang dilakukan seperti pada Gambar 1. Pertama pengumpulan data penduduk yang didapatkan dari Badan Pusat Statistik Kota Bogor. Setelah itu dilakukan perhitungan proyeksi timbulan sampah berdasarkan jumlah data penduduk yang diperoleh sebelumnya. Data penduduk dan proyeksi timbulan sampah dibutuhkan dalam penelitian ini sebagai parameter input untuk algoritma genetika. Algoritma genetika memiliki beberapa tahapan yaitu representasi kromosom, set parameter kemudian dilakukan proses evaluasi populasi dengan operator seleksi, crossover dan mutasi. Dalam penelitian ini data yang dipakai adalah data sekunder. Data sekunder merupakan data yang diperoleh dari Dinas Lingkungan Hidup dan Badan Pusat Statistik kota Bogor.

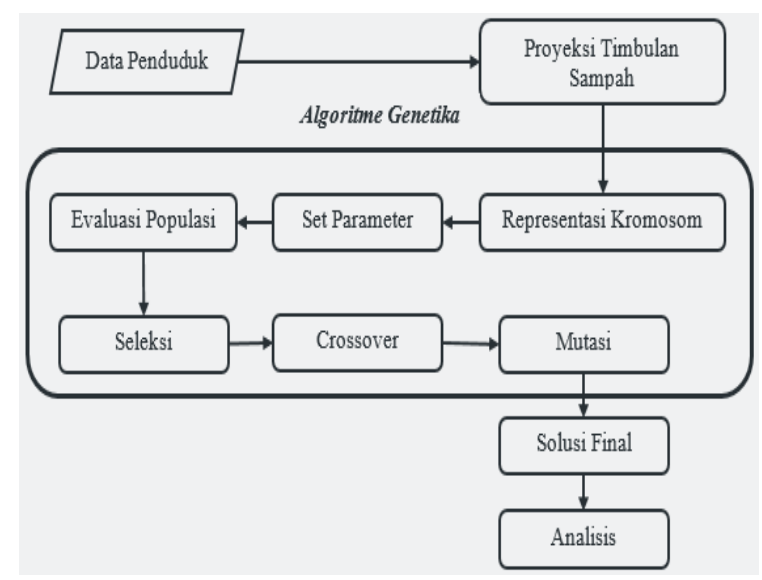

Gambar 1. Tahapan penelitian 


\section{Data Penduduk}

Data penduduk pada penelitian ini merupakan data yang diperoleh dari Badan Pusat Statistik (BPS) Kota Bogor Tahun 2016-2017 seperti terlihat pada Tabel 1.

Tabel 1. Jumlah penduduk dan laju pertumbuhan penduduk kota Bogor

\begin{tabular}{|c|c|c|c|}
\hline \multirow[t]{2}{*}{ Kecamatan } & \multicolumn{2}{|c|}{$\begin{array}{c}\text { Jumlah Penduduk } \\
\text { (Jiwa) }\end{array}$} & \multirow{2}{*}{$\begin{array}{c}\text { Laju } \\
\begin{array}{c}\text { Pertumbuhan } \\
\text { Penduduk } \\
(\%)\end{array} \\
\mathbf{2 0 1 6 - 2 0 1 7} \\
\end{array}$} \\
\hline & 2016 & 2017 & \\
\hline Bogor Barat & 236.302 & 239.860 & 1,51 \\
\hline Bogor Selatan & 199.248 & 201.618 & 1,19 \\
\hline Bogor Timur & 104.737 & 106.029 & 1,23 \\
\hline Bogor Tengah & 104.682 & 104.853 & 0,16 \\
\hline Bogor Utara & 192.812 & 196.051 & 1,68 \\
\hline Tanah Sareal & 226.906 & 232.598 & 2,51 \\
\hline Total & 1.064 .687 & 1.081 .009 & 1,53 \\
\hline
\end{tabular}

Sumber : BPS Kota Bogor

\section{Proyeksi Timbulan Sampah}

Berdasarkan SNI 19-3964-1994 untuk menghitung volume sampah dapat digunakan angka timbulan sampah sebagai berikut:

- Satuan timbulan sampah kota besar $=2-2,50$ L/orang/hari atau $=0,4-0,5 \mathrm{~kg} /$ orang/hari.

- Satuan timbulan sampah kota sedang/kecil $=1,5$ 2L/orang/hari atau $=0,3-0,4 \mathrm{~kg} /$ orang/hari.

Dengan Jumlah penduduk lebih dari satu juta jiwa kota bogor dikategorikan sebagai kota besar sehingga untuk menghitung jumlah timbulan sampah per kecamatan di kota Bogor menggunakan Persamaan 1.

Jumlah Sampah $\left(\mathrm{m}^{3} /\right.$ hari $)=$

$\frac{2.50 \text { liter/orang/hari x jumlah penduduk }}{1000}$

\section{Algoritma Genetika}

Algoritma genetika adalah algoritma pencarian lokal dimulai dari solusi awal yang disebut populasi dan menerapkan operator genetik untuk menemukan solusi yang lebih optimal daripada sebelumnya (Zukhri, 2014). Proses diulangi hingga mencapai batas maksimum iterasi dan setiap kromosom baru sesuai dengan suatu solusi (Kalshetty dan Bashole, 2016). Algoritma genetika merupakan kelas algoritma pencarian stokastik berdasarkan evolusi biologi (Negnevitsky, 2005). Keberagaman pada evolusi biologis adalah variasi dari kromosom antar individu organisme. Variasi kromosom akan mempengaruhi laju reproduksi dan tingkat kemampuan organisme untuk tetap hidup. Dalam penggunaannya algoritma genetika dapat digunakan dalam kasus pencarian jalur alternatif yang menghasilkan rute dengan pemotongan di beberapa node (Trianto et al., 2008), Optimasi penjadwalan mata kuliah dengan menggunakan algoritma genetika (Fauzi, 2015) dan optimasi penjadwalan pengangkutan sampah secara adaptif (Anwari et al., 2014 ).

\section{Representasi Kromosom}

Kromosom merupakan struktur dalam sel makhluk hidup berupa deretan molekul yang terdiri dari berbagai unsur protein yang merupakan informasi genetik suatu organisme (Engelbrecht, 2007; Firdaus, 2016). Pada penelitian ini yang akan dioptimasi adalah pendistribusian truk. Jumlah truk yang berjumlah enam puluh di optimasi dalam pendistribusiannya dimana tiap truk bekerja maksimal tiga kali ritase pengangkutan.

\section{Set Parameter}

Pada algoritma genetika, setelah proses representasi kromosom tahapan berikutnya yaitu menentukan parameter. Pada penelitian ini parameternya yaitu jumlah truk yang beroperasi sebanyak 60 truk, volume sampah kecamatan per hari pada tahun 2017 sebanyak $2701 \mathrm{~m}^{3}$, ritase pengangkutan per truk per hari 3 ritase berdasarkan data yang diperoleh dari Dinas Lingkungan Hidup Kota Bogor. Simulasi parameter dilakukan terhadap jumlah truk pengangkut sampah dan juga jumlah ritase yang menjadi 4 kali, untuk melihat optimasi penyebarannya.

\section{Evaluasi Populasi}

Suatu individu atau kromosom dievaluasi berdasarkan suatu fungsi tertentu sebagai ukuran performasinya. Fungsi yang digunakan untuk mengukur nilai kecocokan disebut fitness function (Hijriana, 2015). Untuk menghitung nilai fitness suatu kromosom diperlukan fungsi matematika untuk menghitung biaya atau berat kromosom. Oleh karena itu setiap kromosom (individu) dapat dievaluasi seberapa besar solusi untuk masalah yang diberikan (Haupt dan Haupt, 2004). mengevaluasi fungsi fitness seperti pada Persamaan 2 (Anwari et al., 2014)

$f=\frac{1}{x+a}$

dimana $x$ merupakan nilai dari individu atau kromosom yang artinya semakin kecil nilai $x$, maka semakin besar nilai fitnessnya tetapi ini akan menjadi masalah jika $x$ bernilai 0 , yang mengakibatkan $f$ bisa bernilai tak hingga. Untuk mengatasinya, $x$ ditambah dengan a merupakan bilangan yang dianggap sangat kecil, agar konvergensi dicapai pada saat diperoleh nilai $f$ terbaik sesuai kriteria.

Pada penelitian ini yang ingin dilakukan adalah melakukan optimasi pendistribusian truk dengan tujuan meminimalisasi sisa sampah yang tidak terangkut, untuk melakukan proses evaluasi parameter yang digunakan yaitu jumlah truk pengangkut sampah, ritase pengangkutan dan total volume sampah Kota Bogor tahun 2017. Dalam 
penelitian ini ada dua objektif yaitu jumlah truk (F1) dan volume sampah yang harus diangkut (F2), penghitungan F1 mengikuti Persamaan 3 dan Persamaan 4, sedangkan penghitungan F2 mengikuti Persamaan 5.

$$
\begin{aligned}
& \mathrm{F}_{1}=\frac{1}{1+\mathrm{C}+\mathrm{a}} \ldots \\
& \mathrm{a}=1-(\mathrm{g} / \mathrm{C})^{2} \\
& \mathrm{~F}_{2}=\frac{1}{1+\mathrm{X}+\mathrm{c}} \ldots \\
& \mathrm{F}=\frac{1}{\mathrm{~F} 1+\mathrm{F} 2} \ldots
\end{aligned}
$$

dimana :

$$
\begin{aligned}
& \mathrm{C}=\text { truk yang belum di assign } \\
& \mathrm{X}=\text { banyaknya TPS } \\
& \mathrm{g}=\text { truk } \\
& \mathrm{c}=\text { volume sampah }
\end{aligned}
$$

Sebagai adaptasi Persamaan 1 ke Persaman 6, dalam penelitian ini ada dua fungsi objektif yaitu F1 dan F2, untuk F1 dibutuhkan variabel $a$ yang diperoleh dari Persamaan 4 (Anwari et al., 2014).

\section{Seleksi}

Setelah evaluasi populasi dilakukan proses seleksi untuk memilih dua individu atau kromosom sebagai induk untuk anak pada generasi berikutnya (Mawaddah dan Mahmudy, 2006). Pada penelitian ini metode yang dipakai yaitu Roullete wheel selection. Metode ini dipilih untuk menghemat waktu yang digunakan pada komputasi. Proses untuk melakukan seleksi dengan metode Roulette wheel yaitu :

1. Menghitung nilai fitness dari masing - masing individu $\left(f_{i}\right)$, dimana $i$ adalah individu ke -1 sampai dengan ke $-n$ ),

2. Menghitung total fitness semua individu,

3. Menghitung probabilitas setiap individu tersebut. Dari nilai fitness setiap individu dihitung nilai total fitness semua individu. Probabilitas individu dicari dengan membagi nilai fitness-nya dengan nilai total fitness semua individu, menggunakan Persamaan 7 (Anwari et al., 2014)

$$
\mathrm{P}[i]=\frac{f(i)}{\sum_{i=1}^{n} f(i)}
$$

dengan $\mathrm{P}[i]=$ Probabilitas individu ke-i dan $f(i)=$ nilai fitness individu ke-i, $\mathrm{i}=1,2,3, \ldots, \mathrm{n}$,

4. Mengacak suatu bilangan $[0,1]$

5. Memilih individu dimana bilangan random tersebut berada sebagai parent

Dalam penelitian ini optimasi dilakukan untuk meminimumkan sampah yang tidak terangkut sehingga diinverskan untuk nilai $\mathrm{F}$ pada Persamaan 6. Nilai $f_{(i)}$ pada Persamaan 7 diperoleh dari
Persamaan 6.

\section{Pindah Silang (Crossover)}

Pindah silang (Crossover) adalah salah satu operator utama dalam algoritme genetika yang bertujuan untuk menghasilkan keragaman individu dalam populasi (Asmoro, 2018). Pindah silang menghasilkan keturunan baru dalam ruang pencarian yang siap diuji. Individu dipilih secara acak untuk dilakukan crossing dengan Probabilitas Crossover (Pc ) antara 0,5 sampai dengan 0,95. Prinsip dari pindah silang ini adalah melakukan operasi (pertukaran aritmatika)pada gen yang bersesuaian dari dua induk untuk mengasilkan individu baru. Proses crossover dilakukan pada setiap individu dengan probabilitas crossover yang ditentukan. Beberapa jenis crossover adalah :

a. One-point crossover (Crossover satu titik)

Pada crossover satu titik string dipecah menjadi dua bagian, satu bagian ditukarkan dengan satu bagian dari string yang lain yang sudah dipisahkan dengan cara yang sama.

b. Two-point crossover (Crossover dua titik)

Proses crossover ini dilakukan dengan memilih crossover dua titik. Keturunannya (offspring) dibentuk oleh urutan bit dari kromosom awal ke titik crossover pertama, disalin dari induk pertama, bagian dari titik crossover pertama dan kedua disalin dari induk kedua, dan kemudian yang lain disalin dari induk pertama.

c. N-point / Uniform crossover

Crossover yang seragam menghasilkan keturunan dengan cara menyalin bit secara acak dari kedua orang tua (parents). Secara skematis proses crossover pada Gambar 2.

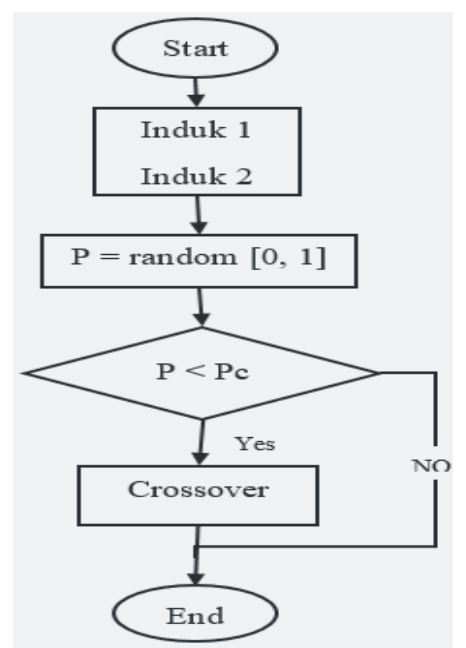

Gambar 2. Sistematika proses crossover (CO)

\section{Mutasi}

Mutasi merupakan operator yang menukar nilai gen secara acak (Lukas et al., 2005). Mutasi dilakukan dengan memberikan nilai inversi atau menggeser nilai gen pada gen terpilih untuk dimutasikan (Sofwan et al., 2008). Menurut Basuki 
(2003) proses mutasi dilakukan setelah menjalankan crossover kromosom dan jumlah mutasi gen didapat dari probabilitas mutasi (Pm). Tujuan dari mutasi adalah untuk menjaga keragaman dari karakteristik genetik dari suatu populasi (Cao et al., 2011). Secara skematis proses mutasi dapat di gambarkan pada Gambar 3.

\section{Solusi Final}

Solusi final untuk proses optimasi distribusi truk pengangkut sampah di Kota Bogor yaitu berupa rekomendasi jumlah truk yang didistribusikan ke kecamatan.

\section{HASIL DAN PEMBAHASAN}

Jumlah penduduk Kota Bogor berdasarkan data yang diperoleh dari Badan Pusat Statistik (BPS) Kota Bogor pada tahun 2016 sebanyak 1.064.687 Jiwa dan pada tahun 2017 sebanyak 1.081.009 Jiwa. Berdasarkan Tabel 1 diperoleh bahwa laju pertumbuhan penduduk Kota Bogor 2016-2017 sekitar $1,53 \%$.

\section{Proyeksi Timbulan Sampah}

Proyeksi timbulan sampah kecamatan per hari (Gambar 3) tahun 2016 dan 2017 dapat dihitung menggunakan Persamaan 3 berdasarkan data jumlah penduduk yang didapatkan dari Badan Pusat Statistik Kota Bogor.

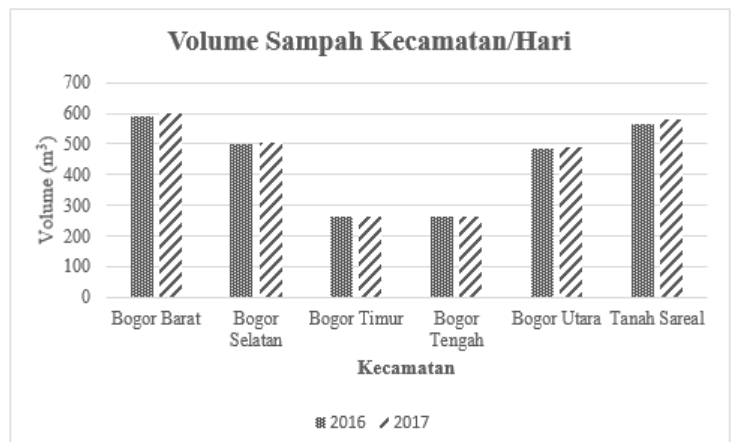

Gambar 3. Volume sampah kecamatan/hari tahun 2016- 2017

Berdasarkan data jumlah penduduk dan perhitungan volume sampah diperlihatkan pada Gambar 7 pada tahun 2016 volume sampah harian Kota Bogor sebanyak $2659 \mathrm{~m}^{3}$ dan pada tahun 2017 mengalami kenaikan menjadi $2701 \mathrm{~m}^{3}$. Dengan keterbatasan armada pengangkut sampah yang dimiliki oleh DLH Kota Bogor maka diupayakan untuk mengoptimalkan pembagian truk yang berkapasitas $7 \mathrm{~m}^{3}$ dengan metode algoritma genetika agar sampah bisa diangkut semaksimal mungkin. Adapun jumlah TPS pada tiap kecamatan sangat bervariasi baik jumlah ataupun volume sampah yang ada seperti yang ditunjukkan pada Tabel 2 .

Tabel 2. Jumlah TPS dan volume sampah per hari tahun 2017

\begin{tabular}{lcc}
\hline Kecamatan & $\begin{array}{c}\text { Jumlah } \\
\text { TPS }\end{array}$ & $\begin{array}{c}\text { Volume Sampah } \\
\left(\mathbf{m}^{\mathbf{3}}\right)\end{array}$ \\
\hline Bogor Barat & 85 & 599 \\
Bogor Selatan & 62 & 504 \\
Bogor Timur & 70 & 265 \\
Bogor Tengah & 121 & 262 \\
Bogor Utara & 63 & 490 \\
Tanah Sareal & 89 & 581 \\
\hline \multicolumn{1}{c}{ Total } & 490 & 2701
\end{tabular}

${ }^{\text {*) Berdasarkan jumlah penduduk pada masing-masing }}$ kecamatan

\section{Representasi Kromosom}

Jumlah truk yang berjumlah enam puluh truk tersebut direpresentasikan sebagai kromosom dalam bentuk bilangan bulat. Adapun bentuk representasi kromosom digambarkan pada Tabel 3 dan penyebaran paket pengambilan sampah yang harus dilayani disajikan pada Tabel 4.

Tabel 3. Representasi kromosom

\begin{tabular}{|c|c|c|c|}
\hline Truk & Ritase & Kecamatan & $\begin{array}{l}\text { Ritase yang } \\
\text { dibutuhkan }\end{array}$ \\
\hline 1 & 1 & 1 & 1 \\
\hline 2 & 1 & 2 & 1 \\
\hline 3 & 1 & 3 & 1 \\
\hline 4 & 1 & 4 & 1 \\
\hline 5 & 1 & 5 & 1 \\
\hline 6 & 1 & 6 & 1 \\
\hline 1 & 2 & 1 & 2 \\
\hline 2 & 2 & 2 & 2 \\
\hline 3 & 2 & 3 & 2 \\
\hline 4 & 2 & 4 & 2 \\
\hline 5 & 2 & 5 & 2 \\
\hline 6 & 2 & 6 & 2 \\
\hline 1 & 3 & 1 & 3 \\
\hline 2 & 3 & 2 & 3 \\
\hline 3 & 3 & 3 & 3 \\
\hline 4 & 3 & 4 & 3 \\
\hline 5 & 1 & 5 & 3 \\
\hline . & . & . & . \\
\hline$\cdot$ & . & . & . \\
\hline 60 & 1 & 6 & 86 \\
\hline
\end{tabular}


Tabel 4. Penyebaran paket pengambilan sampah yang harus dilayani

\begin{tabular}{lc}
\hline \multicolumn{1}{c}{ Kecamatan } & Ritase yang dibutuhkan \\
\hline Bogor Barat & 86 \\
Bogor Selatan & 72 \\
Bogor Timur & 38 \\
Bogor Tengah & 37 \\
Bogor Utara & 70 \\
Tanah Sareal & 83 \\
\hline \multicolumn{1}{c}{ Total } & 386 \\
\hline
\end{tabular}

\section{Evaluasi Crossover dan Mutasi}

Dalam penelitian ini dilakukan pengujian pengaruh nilai Probabilitas crossover $(\mathrm{Pc})$ dan Probabilitas mutasi (Pm) terhadap waktu eksekusi untuk melihat konvergensi nilai parameter yang diuji. Menurut Firdaus (2016) untuk penentuan parameter probabilitas crossover dan mutasi dicoba dengan beberapa masukan nilai dimana nilai acuan dirujuk dari Arkeman et al. (2012), yaitu antara 0,5 sampai dengan 0,95. Hasil pengujian Pc dan Pm disajikan pada Tabel 5.

Hasil perhitungan populasi dengan memasukkan beberapa nilai, maka Pc yang dipilih adalah $\mathrm{Pc}=0,5$ dan $\mathrm{Pm}=0,2$ untuk nilai parameter yang cepat dan stabil mencapai konvergen (Tabel 6). Selain nilai Pc dan Pm, dilakukan pengujian yang ditunjukkan pada Tabel 6 untuk melihat pengaruh jumlah populasi terhadap waktu eksekusi. Dari kedua pengujian yang dilakukan Tabel 5 dan Tabel 6 terlihat perubahan $\mathrm{Pm}, \mathrm{Pc}$ dan populasi awal mempengaruhi waktu eksekusi dan yang paling besar pengaruhnya adalah jika nilai Pc dan Pm berubah dengan gap yang cukup besar.

\section{Solusi Final}

Solusi final yang diharapkan pada penelitian ini adalah optimasi pendistribusian truk pengangkut sampah menggunakan algoritma genetika agar pendistribusian truk ke kecamatan di Kota Bogor lebih optimal. Pengujian dilakukan sebanyak 10 kali percobaan atau running program dengan memasukkan data nilai ritase pengangkutan yang berbeda yaitu 3 ritase dan 4 ritase dengan jumlah truk yang berbeda-beda, dan hasil perhitungannya diperlihatkan pada Tabel 7. Selain pengujian untuk layanan pengangkutan 3 ritase, dilakukan pengujian dengan meningkatkan ritase pengangkutan menjadi 4 ritase.

Tabel 5. Pengujian Pc dan Pm

\begin{tabular}{ccccc}
\hline No & Populasi Awal & Pc & Pm & $\begin{array}{c}\text { Waktu eksekusi } \\
\text { (detik) }\end{array}$ \\
\hline 1 & 180 & 0,5 & 0,2 & 2.611034 \\
2 & 180 & 0,5 & 0,5 & 2.688233 \\
3 & 180 & 0,6 & 0,2 & 2.650434 \\
4 & 180 & 0,6 & 0,5 & 2.661848 \\
5 & 180 & 0,7 & 0,2 & 2.661992 \\
6 & 180 & 0,7 & 0,5 & 2.702195 \\
\hline
\end{tabular}

Tabel 6. Pengujian pengaruh populasi

\begin{tabular}{ccccc}
\hline No & Populasi & Pc & Pm & $\begin{array}{c}\text { Waktu eksekusi } \\
\text { (detik) }\end{array}$ \\
\hline 1 & 60 & 0,5 & 0,2 & 1.279608 \\
2 & 70 & 0,5 & 0,2 & 1.457931 \\
3 & 80 & 0,5 & 0,2 & 1.559899 \\
4 & 90 & 0,5 & 0,2 & 1.610908 \\
5 & 100 & 0,5 & 0,2 & 1.704652 \\
6 & 110 & 0,5 & 0,2 & 1.753643 \\
\hline
\end{tabular}

Tabel 7. Pengujian ritase

\begin{tabular}{|c|c|c|c|c|c|c|c|c|c|c|c|c|}
\hline \multirow{3}{*}{ Kecamatan } & \multicolumn{6}{|c|}{3 ritase } & \multicolumn{6}{|c|}{4 ritase } \\
\hline & \multicolumn{6}{|c|}{ Jumlah Truk } & \multicolumn{6}{|c|}{ Jumlah Truk } \\
\hline & 60 & 70 & 80 & 90 & 100 & 110 & 60 & 70 & 80 & 90 & 100 & 110 \\
\hline Bogor Barat & 16 & 17 & 20 & 27 & 33 & 33 & 14 & 16 & 24 & 25 & 29 & 38 \\
\hline Bogor Selatan & 10 & 13 & 14 & 14 & 15 & 23 & 11 & 12 & 13 & 17 & 15 & 16 \\
\hline Bogor Timur & 7 & 9 & 11 & 6 & 10 & 8 & 8 & 11 & 6 & 6 & 10 & 7 \\
\hline Bogor Tengah & 6 & 5 & 7 & 5 & 8 & 7 & 5 & 5 & 6 & 5 & 8 & 6 \\
\hline Bogor Utara & 9 & 11 & 13 & 13 & 11 & 10 & 9 & 12 & 10 & 16 & 14 & 13 \\
\hline Tanah Sareal & 12 & 15 & 15 & 25 & 23 & 29 & 13 & 14 & 21 & 21 & 24 & 30 \\
\hline
\end{tabular}


Berdasarkan hasil optimasi yang dilakukan menggunakan algoritme genetika dengan jumlah truk sebanyak 60 truk dengan ritase pengangkutan sebanyak 3 ritase diperoleh hasil seperti Tabel 7 . Hasil optimum yang diperoleh untuk pendistribusian truk yaitu Kecamatan Bogor Barat 16 truk, Bogor Selatan 10 truk, Bogor Timur 7 truk, Bogor Tengah 6 truk, Bogor Utara 9 truk dan Tanah Sareal 12 truk. Dari hasil optimasi tersebut ditunjukkan persentase sampah yang terangkut dari total sampah di tiap-tiap kecamatan pada Tabel 8 . Tabel 8 menunjukkan pendistribusian truk yang optimal menggunakan algoritme genetika ke tiap-tiap kecamatan dan persentase sampah yang terangkut.

Sebelum dilakukan proses optimasi menggunakan algoritme genetika pendistribusian truk belum optimal. Pendistribusian merata ke semua kecamatan walaupun kebutuhan truk berbeda berdasarkan volume sampah yang berbeda di tiap kecamatan. Tabel 8 dilihat dengan jumlah truk yang sama dalam mengangkut sampah tidak optimal, Kecamatan Bogor Barat dengan jumlah sampah yang paling besar hanya terangkut sebanyak 35,05\% sedangkan Kecamatan Bogor Tengah yang memiliki sampah setengah dari Kecamatan Bogor Barat diangkut sebanyak $80,15 \%$.

Selain itu, untuk menunjukkan bahwa hasil optimasi untuk pendistribusian truk pengangkut sampah menggunakan algoritme genetika dilakukan pernghitungan standar deviasi untuk melihat sebaran tersebut optimum. Hasil penghitungan standar deviasi berdasarkan volume sampah kecamatan yang ada pada Tabel 8 menggunakan persamaan 8 .

$$
s=\sqrt{\frac{n \sum_{i=1}^{n} x_{i}^{2}-\left(\sum_{i=1}^{n} x_{1}\right) 2}{n(n-1)}}
$$

dimana :

$$
\begin{array}{ll}
s & =\text { Standar deviasi } \\
\mathrm{n} & =\text { Ukuran sampel } \\
x & =\text { Rata-rata } \\
x_{i} & =\text { Nilai } \mathrm{x} \text { ke-i }
\end{array}
$$

Dari hasil penghitungan nilai standar deviasi diperoleh hasil bahwa pendistribusian dari hasil optimasi menggunakan algoritme genetika diperoleh nilai standar deviasi sebesar 7,32 sedangkan yang tidak dioptimasi nilai standar deviasinya sebesar 21,27. Nlai standar deviasi yang kecil menunjukkan persentase sampah yang berhasil diangkut di tiap TPS itu relatif sama sedangkan yang tidak optimal itu ditunjukkan dengan nilai standar deviasi yang besar dimana sampah ada yang tidak terangkut.

Tabel 9 menunjukkan hasil pengujian ritase pengangkutan yang berbeda dengan jumlah truk yang ada saat ini adalah 60 truk. Dari hasil pengujian dilihat jika truk milik DLH yang beroperasi saat ini beroperasi sebanyak 3 ritase setiap harinya hanya mampu mengangkut sampah Kota Bogor sebanyak $50,35 \%$, tetapi jika ritase pengangkutan menjadi 4 kali ritase sehari, sampah yang dapat diangkut sebanyak $62,19 \%$.

Berdasarkan pengujian yang dilakukan dengan membandingkan Tabel 9, jika ritase pengangkutan sebanyak 3 ritase dan solusi yang ditawarkan adalah penambahan truk maka untuk mengangkut sampah sebanyak $62.19 \%$ dibutuhkan 80 truk, sedangkan jika pengangkutan dilakukan sebanyak 4 ritase hanya dibutuhkan truk pengangkut sebanyak 60 truk.

Tabel 9. Perbandingan daya angkut

\begin{tabular}{lcc}
\hline \multirow{2}{*}{ Kecamatan } & \multicolumn{2}{c}{ 60 truk } \\
\cline { 2 - 3 } & 3 ritase & 4 ritase \\
\hline Bogor Barat & 336 & 392 \\
Bogor Selatan & 210 & 308 \\
Bogor Timur & 147 & 224 \\
Bogor Tengah & 126 & 140 \\
Bogor Utara & 189 & 252 \\
Tanah sareal & 352 & 364 \\
Total & 1360 & 1680 \\
\hline
\end{tabular}

Tabel 10 menunjukkan sampah yang terangkut jika solusi yang dipilih yaitu menambah jumlah truk berkapasitas $7 \mathrm{~m}^{3}$ dengan layanan pengangkutan sebanyak tiga kali ritase pengangkutan.

Tabel 8. Distribusi truk

\begin{tabular}{lcccccc}
\hline \multirow{2}{*}{ Kecamatan } & \multicolumn{2}{c}{ Optimal } & \multicolumn{2}{c}{ Tidak Optimal } \\
\cline { 2 - 6 } & Truk & Ritase & $\begin{array}{c}\text { Sampah terangkut } \\
(\boldsymbol{\%})\end{array}$ & Truk & Ritase & $\begin{array}{c}\text { Sampah terangkut } \\
(\boldsymbol{\%})\end{array}$ \\
\hline Bogor Barat & 16 & 48 & 56,09 & 10 & 30 & 35,05 \\
Bogor Selatan & 10 & 30 & 41,66 & 10 & 30 & 41,66 \\
Bogor Timur & 7 & 21 & 55,47 & 10 & 30 & 79,24 \\
Bogor Tengah & 6 & 18 & 48,1 & 10 & 30 & 80,15 \\
Bogor Utara & 9 & 27 & 38,57 & 10 & 30 & 42,85 \\
Tanah Sareal & 12 & 36 & 43,37 & 10 & 30 & 36,14 \\
\hline
\end{tabular}


Tabel 10. Volume sampah terangkut hasil optimasi

\begin{tabular}{lccccccc}
\hline \multirow{2}{*}{ Kecamatan } & Total sampah / hari & \multicolumn{5}{c}{ Jumlah Truk } \\
\cline { 3 - 7 } & $\left(\mathbf{m}^{\mathbf{3}}\right)$ & $\mathbf{6 0}$ & $\mathbf{7 0}$ & $\mathbf{8 0}$ & $\mathbf{9 0}$ & $\mathbf{1 0 0}$ & $\mathbf{1 1 0}$ \\
\hline Bogor Barat & 599 & 336 & 357 & 420 & 567 & 693 & 693 \\
Bogor Selatan & 504 & 210 & 273 & 294 & 294 & 315 & 483 \\
Bogor Timur & 265 & 147 & 189 & 231 & 126 & 210 & 168 \\
Bogor Tengah & 262 & 126 & 105 & 147 & 105 & 168 & 147 \\
Bogor Utara & 490 & 189 & 231 & 273 & 273 & 231 & 210 \\
Tanah Sareal & 581 & 252 & 315 & 315 & 525 & 483 & 609 \\
\hline
\end{tabular}

\section{Implikasi Manajerial}

Algoritma genetika dapat diterapkan untuk mengoptimalkan pendistribusian truk pengangkut sampah ke kecamatan di Kota Bogor untuk meminimalisasi sampah yang tidak terangkut. Dari hasil pengujian yang dilakukan jika solusi yang dipilih adalah penambahan truk hal yang harus diperhatikan yaitu kondisi infrastruktur Kota Bogor, kondisi lalu lintas sepanjang jalan dari TPS-TPS menuju TPA Galuga. Selain itu, harus diperhatikan dari segi ekonomis biaya untuk truk baru, biaya bahan bakar dan luas jalan saat ini agar penambahan truk efektif. Sebaliknya, jika yang ingin ditambahkan adalah ritase pengangkutan berarti jam kerja bertambah. Untuk solusi tersebut perlu dipertimbangkan ketersediaan sumber daya manusia yang dimiliki DLH dan biaya operasional tambahan untuk jam kerja yang melebihi standar sebelumnya. Selain itu, agar lebih efektif bisa diterapkan teknologi monitoring pemantauan posisi driver agar jadwal pengangkutan sampah di Kota Bogor lebih terkontrol. Jika kedua solusi tersebut dibandingkan, maka penambahan ritase pengangkutan lebih available baik dari sisi ekonomi dan efisiensi waktu.

\section{KESIMPULAN DAN SARAN}

\section{Kesimpulan}

Opimasi distribusi truk pengangkut sampah dapat dilakukan dengan menggunakan algoritme genetika. Hasil penelitian menunjukkan jumlah truk yang harus didistribusikan ke tiap-tiap kecamatan di Kota Bogor dimana pendistribusian tersebut dipengaruhi oleh jumlah volume sampah harian kecamatan. Hasil ini ditunjukkan oleh nilai standar deviasi antara yang optimum dengan yang tidak optimum dimana hasil optimasi yang optimum nilai standar deviasinya sebesar 7.32 dan yang tidak optimum nilai standar deviasinya adalah 21.127. Dengan pertimbangan dari sisi ekonomi dan efisiensi waktu, solusi yang diberikan yaitu penambahan jumlah ritase pengangkutan.

\section{Saran}

1. Melibatkan kondisi kepadatan lalu lintas sebagai parameter waktu operasi pengangkutan (ritase pengangkutan)
2. Meningkatkan kegiatan pengurangan sampah seperti 3R,bank sampah dan pengomposan untuk mengurangi beban angkut sampah menuju TPA Galuga.

3. Penelitian berikutnya diharapkan melakukan optimasi lebih detail hingga ke level TPS.

\section{DAFTAR PUSTAKA}

Anwari N, Fariza A, dan Prasetyaningrum S. 2014. Optimasi penjadwalan pengangkutan sampah di Surabaya secara adaptif menggunakan metode algoritme genetika. SCAN. IX (1). ISSN : 1978-0087

Arkeman Y, Seminar KB, dan Gunawan H. 2012. Algoritme genetika teori dan aplikasinya untuk bisnis dan industri. Bogor (ID): IPB Press.

Arnantha M. 2012. Studi optimasi teknis operasional pengumpulan dan pengangkutan sampah dengan model simulasi. Jurnal Ilmiah Teknik Sipil, 16 (1).

Asmoro G. 2018. Development of truck scheduling system using genetic algorithm (case study cross docking ahm company). [skripsi]. Bogor (ID) : Institut Pertanian Bogor.

Basuki A. 2003. Algoritme Genetika Suatu Alternatif Penyelesaian Permasalahan Searching, Optimasi, Dan Mechine Learning. PENS - ITS Surabaya.

[BPS] Badan Pusat Statistik Kota Bogor. 2018. Penduduk kota bogor menurut kecamatan dan rasio jenis kelamin. [Internet]. [Diunduh 2017 Desember 20]. Tersedia pada: https://bogorkota.bps.go.id/statictable/2018/0 5/14/114/penduduk-kota-bogor-menurutkecamatan-dan-rasio-jeniskelamin2016.html

Cao K, Batty M, Huang B, Liu Y, Yu L, Chen J. 2011. Spatial multiobjective land use optimization:extensions to the non-dominated sorting genetic algorithm-II. International Journal Geographical Information Science 25 (12): 1949-1969. doi.org/10.1080/ 13658816.2011.570269

Engelbrecht P.2007. Computational Intelligence An Introduction, $2^{\text {ed }}$. England: John Wiley \& Sons Ltd. 
Fauzi R. 2015. Optimasi penjadwalan mata kuliah dengan menggunakan algoritme genetiuka (studi kasus program studi teknik informatika Universitas Darma Persada). [Skripsi]. Jakarta (ID) : Universitas Darma Persada

Firdaus. 2016. Perencanaan penggunaan lahan industri biodiesel berkelanjutan menggunakan algoritme genetika tujuan jamak. [Tesis]. Bogor (ID) : Institut Pertanian Bogor.

Haupt dan Haupt. 2004. Practical Genetic Algorithms, Secondedition. United State of America (USA) : John Wiley \& Sons Inc Publication.

Harrison C, Eckman B, Hamilton R, Hartswick P, Kalagnanam J, Paraszczak J, Williams P. 2010. Foundations for smarter cities. IBM Journal of Research and Development. 54: 4. $1-16$.

Hasibuan M, dan Lusiana. 2015. Pencarian rute terbaik pada travelling salesman problem (TSP) menggunakan algoritme genetika pada dinas kebersihan dan pertamanan kota pekanbaru. SATIN-Sains dan Teknologi Informasi. 1 (1).

Hijriana N. 2015. Penerapan metode algoritme genetika untuk permasalahan penjadwalan perawat (nurse scheduling problem). Info Teknik. 16 (1): 61-74.

Kalshetty Y, dan Bhosale P. 2016. Genetic algorithm for job shop scheduling. International Journal Innovations In Engineering And Technology. 7. ISSN: 2319 - 1058. P358

Kurniawan B. 2008. Aplikasi algoritme genetika untuk optimasi penjadwalan kegiatan perkuliahan. Jurnal Transformatika. 6 (1): $1-8$.

Kusumadewi S. 2003. Artificial Intelligence: Teknik dan Aplikasinya. Yogyakarta (ID): Graha Ilmu.

Lukas S, Toni A, dan Yuliani W. 2005. Penerapan algoritme genetika untuk traveling salesman problem dengan menggunakan metode order crossover dan insertion mutation. Seminar Nasional Aplikasi Teknologi InformasiSNATI2005. Yogyakarta: 18 Juni 2005. ISBN: 979-756-061-6.
Mawaddah NK dan Mahmudy WF. 2006. Optimasi penjadwalan ujian menggunakan algoritme genetika. Kursor. 2 (2):1-8

Moengin P. 2011. Metode Optimasi. Bandung (ID): Muara Indah

Muliadi. 2014. Pemodelan Algoritme Genetika Pada Sistem Penjadwalan Perkuliahan Prodi Ilmu Komputer Universitas Lambung Mangkurat. Jurnal Ilmu Komputer. 1(01). ISSN: 24067857

Negnevitsky M. 2005. Artificial Intelligence: A Guide To Intelligent Systems. 2 ${ }^{\text {ed }}$. United Kingdom (UK): Addison Wesley Publisher

Pramono. 2018. Optimasi perencanaan infrastruktur pengelolaan sampah dengan pemodelan program linier. [Tesis]. Surakarta (ID) : Universitas Muhammadiyah Surakarta.

Putu. 2014. Smart City Beserta Cloud Computing Dan Teknologi-Teknologi Pendukung Lainnya. Bandung (ID): Informatika.Hal 93102

Sofwan A, Handoyo E, dan Ramdhony. 2008. Algoritme genetika dalam pemilihan spesifikasi komputer. Seminar Nasional Aplikasi Teknologi Informasi 2008 (SNATI 2008). ISSN: 1907-5022

Standar Nasional Indonesia: SNI 19-3964-1994 Metode pengambilan dan pengukuran contoh timbulan dan komposisi sampah perkotaan

Trianto N, Wahyu PJ, dan Agus HN. 2008. Algoritma genetika dalam pencarian jalur alternatif. jurnal informatika. 4 (1).

Umar N. 2014. Aplikasi Algoritma genetika untuk menyelesaikan Travelling Salesman Problem (TSP). Journal of Technology Research Informatioan-JTRISTE. 1 (2) : 50-57.

Zukhri Z. 2014. Algoritme Genetika Metode Komputasi Evolusioner Untuk Menyelesaikan Masalah Optimasi. Yogyakarta (ID): ANDI. 